\title{
How the Coronavirus Inspired Teaching the Diffusion of Innovation Theory
}

\author{
DEIRDRE DINGMAN, DrPH ${ }^{1}$; SARAH BAUERLE BASS, PHD ${ }^{1,2}$ \\ ${ }^{1}$ Department of Social and Behavioral Sciences, College of Public Health, Temple University \\ ${ }^{2}$ Risk Communication Laboratory, College of Public Health, Temple University \\ Correspondence: deirdre.dingman@,temple.edu (Deirdre Dingman)
}

\begin{abstract}
Many public health courses include content on behavior change theories, including the Diffusion of Innovation Theory (DoI). In DoI, innovations are adopted based on 5 characteristics: the innovation's relative advantage of what came before, its compatibility with a person or group's culture, the complexity of the innovation, whether the innovation can be tried before fully adopted, and whether or not the effects of adopting this innovation can be observed in others. This paper describes the application of the public health response to COVID-19 in the US as a dynamic example with which to teach DoI theory in the context of an undergraduate program planning and evaluation class. Because students were forced into an online environment when essential businesses closed in an effort to 'flatten' the coronavirus curve, we describe the unique way the outbreak could be used in an organic online discussion in which students could use their own current experiences to extrapolate to the DoI constructs. While not done as a formal "lesson plan", we describe the students' engagement, provide commentary of their application of DoI to the COVID-19 response, and suggest how more formal exercises could be incorporated into undergraduate public health curriculum.
\end{abstract}

\section{How the Coronavirus Inspired Teaching the Diffusion of Innovation Theory}

In most public health degree programs, students are introduced to basic behavior change theories and their key concepts. Instructors may provide relevant real-life examples to engage students as they walk through a theory's concepts. For example, using influenza as the health threat and vaccination as the behavior to adopt in explaining the Health Belief Model $^{1}$ or using sexually transmitted infections as the health threat and condom use as the behavior to adopt in explaining Social Cognitive Theory. ${ }^{2}$ Diffusion of Innovation Theory (DoI) is also commonly addressed in public heath courses, especially communitybased program planning and health communication as a way to explain uptake of interventions or messages ${ }^{3,4}$, among others. In the undergraduate public health program planning and evaluation class taught in the authors' College of Public Health, a common example behavior to teach DoI constructs had been cell phone use. But in the Spring of 2020, COVID -19 forced all classes online and gave us the opportunity to offer a near perfect example to work through the concepts of DoI. This paper describes our process, how students reacted, and offers suggestions for expanded use through more formal pedagogy. 


\section{Diffusions of Innovation Theory}

From cell phone adoption to "flattening the curve" (i.e., spreading new infections out over time), DoI theory can be used to explain how an innovation (e.g., a behavior) is communicated to a certain group or population (e.g., persons at risk for a certain disease).5, 6 The goal of DoI in public health is to get the innovation to work its way through a population so that the majority adopt the behavior and disease risk lowers. The innovations are adopted based on 5 characteristics: the innovation's relative advantage of what came before, its compatibility with a person or group's culture, the complexity of the innovation, whether the innovation can be tried before fully adopted, and whether or not the effects of adopting this innovation can be observed in others. In addition to considering these characteristics, Rogers ${ }^{6}$ suggests categories for the adoption of the innovation. The categories from quickest to slowest adopters are innovator, early adopter, early majority, late majority and laggards. For example, a person using a flip phone in 2020 has clearly 'lagged' behind, where as a person with the newest iPhone is an early adopter, if not an innovator.

The DoI adoption patterns have been well studied ${ }^{7}$ and health campaigns that target specific categories have found success. ${ }^{8}$ Here we provide details on a class exercise which considers how a behavior required during an exigent health crisis is diffused, paying particular attention to the five characteristics noted above. The experience described is one that occurred in real-time without the luxury of lesson planning and formal assessment, but with subjective success (e.g., the energy in the 'room', student engagement). The ability to adapt lessons to exigent crisis is an example of innovative teaching and is highlighted here.

\section{Context}

Though reports of a new coronavirus were widespread in the winter/spring of 2020, evidence suggests that SARS-CoV2, the virus that causes COVID-19, emerged in December 2019. ${ }^{9}$ The United States first identified cases in January and community spread was evident by March. ${ }^{9}$ Both the international and national response to the spread of this new coronavirus continues to be the subject of critique and debate in scholarly and popular media. At the earliest stages, states suggested protective measures including washing hands, not touching the face and practicing social distancing. Mask wearing was discussed as something that could be done. Public health officials urged the public to adopt these measures to 'flatten the curve.' In Philadelphia Pennsylvania, where the authors' institution is located, both the mayor and Governor implemented stay at home orders and closing of non-essential businesses in mid-March 2020.10, 11

At around the same time and as cases of COVID-19 began to rise, it was clear that gathering indoors was the greatest risk factor for transmission. ${ }^{12}$ The first major university closure took place in Washington on March $6^{\text {th }},{ }^{13}$ and by the middle of March more than 1000 colleges across the country had moved to fully online instruction. ${ }^{14}$ The authors' University also reacted early, sending students home and putting all courses online.

The public health course (SBS 3596) used as a case study here is an upper-level program planning class for public health undergraduate majors. It is a small (15 to 20 students), writing intensive, two-semester capstone experience that, along with concurrent courses, prepares juniors and seniors for communitybased internships. Students are introduced to behavior change and learning theories and develop practical skills for implementing programs. ${ }^{15}$ When campus closed, the second semester of the course was in progress and DoI theory was being discussed in the context of communicating and marketing 
community-based public health programs. SBS 3596 is usually taught in person twice a week, and was pivoted to a twice a week on line, synchronous course due to the coronavirus pandemic of 2020-2021.

\section{Activity}

DoI theory had been introduced in the first semester which all students attended, so they only needed a refresher on the main concepts. As the COVID-19 pandemic unfolded, prevention mandates were used as examples for students to discuss how and why certain directives - handwashing, not touching your face, social distancing, mask wearing - were or were not being adopted by the public according to the theory's constructs. Handwashing had been covered before campus closed and we had talked about logistical problems, more than noncompliance. For example, the bathrooms ran out of paper towel and soap. The first organized impromptu class lesson using DoI covered the new concepts of social distancing and mask wearing, with the focus on masks. The lesson is considered impromptu because the original lesson plan involved walking through getting persons to accept the flu vaccine.

\section{Mask Wearing}

In March and April of 2020, most people in Philadelphia and its suburbs took the social distancing mandate seriously and stayed home except for those in positions deemed essential (e.g., pharmacists, grocery store clerks). This was especially true for persons over the age of 65 or those who had chronic conditions that put them at higher risk. ${ }^{16}$ Students talked openly about family members they were worried about and the memes making their way through social media urging younger groups "not to kill grandpa".

Early advice on mask wearing from the Centers for Disease Control and Prevention (CDC) stated that persons who had symptoms of COVID-19 or who had been diagnosed with COVID-19 should wear a certain kind of mask (N95 respirators and surgical masks) if they went out in public, which they should avoid if possible. In fact, the CDC encouraged asymptomatic people NOT to wear masks. ${ }^{17}$ So, our first discussion about masks explored why people were wearing them when there was no scientific evidence to support that general mask wearing was warranted. These were casual discussions at the start of each class, more like touching base and myth checking, which evolved into learning opportunities when DoI was reintroduced

For the structured DoI lesson, students were taken through the five characteristics and communication channels with an interactive lecture. Students were then put in four virtual small groups via Zoom breakout rooms and given a target population (i.e., college aged persons, adults aged 30 to 60, older adults, adults with chronic diseases) and asked to consider the concept of social distancing through the lens of the theory. The students also considered messaging to specific categories, e.g., laggards. Below are the ideas that students presented along with commentary as things evolved after the course ended in May 2020.

\section{Relative Advantage}

The contradictions in messaging created mask confusion and provided an important point of student discussion on how relative advantage may be affected by context and high-level messaging. For example, initial CDC guidance was that only certain people wear masks so health communications could be twofold, and students noted this. The CDC was encouraging a certain group to wear a mask and another not to. This led to a point of contention: whether to spend energy or resources telling people not to wear masks as on one hand, it would not hurt the person, but on the other, it could reduce supply. The 
contradictions allowed students to see how things that occur and are not planned for in a health communication or health education intervention may change how the audience is receptive to the innovation. But in March, it was hard to make a case for relative advantage. Students noted that the relative advantage when the message changed could be is the risk of catching the virus lower if all persons wear a mask than if only symptomatic/infected persons wear a mask.'Another comparison was if wearing a mask over not wearing a mask was better. For most persons not used to wearing a mask, not having to wear one would be an obvious advantage.

Compatibility

Compatibility with mask wearing has been the greatest challenge for diffusion. Most people alive in the United States today had never worn masks to avoid a virus. But in 2020, mask wearing became a political battle over individual freedom and presidential endorsement. Unfortunately, this polarization is not new - but that means it should have been foreseen. Some communities resisted mask wearing during the 1918 pandemic as well, but communities that did not resist, those that followed the quick, early guidance, were able to flatten their curves expediently. ${ }^{22}$ Those communities that did not follow the guidance saw increases in infection. So students noted that this theory attribute has mixed results, meaning it was positive only for those who say mask wearing is compatible with their beliefs.

\section{Complexity}

On the face of it this innovation is not complicated. Midway through the first wave, however, the CDC ${ }^{23}$ was compelled to offer 'how to' fact sheets and videos to the public via their website and social media. The biggest issue was and continues to be the lack of coverage for the nose. In fact, at the end of June 2020, a popular writer gave names for all the wrong ways people wear masks, for example 'the reverse batman' for those who do not cover their nose. ${ }^{24}$ In the context of DoI theory, students noted that this lack of understanding on how to wear a mask correctly made the diffusion of this innovation less likely.

\section{Trialability}

Yes, one could try to wear a mask and then decide they did not want to. Here people might try switching types of masks, and as above, wearing them incorrectly as a compromise to themselves or those who might provide peer pressure. This did play out with a switch from KN95 to cloth masks as being more comfortable but still effective enough for non-medical workers. In this respect, according to students, this theory attribute would encourage mask wearing.

\section{Observability}

Data have shown that those areas with better compliance with mask wearing and social distancing have lower incidence of COVID-19. ${ }^{25}$ Conversely, the media also shows us people at events not wearing masks who later contract the illness, providing an implied connection. So this theory construct should be a positive attribute, i.e., seeing people wearing masks is protective. But students shared that because mask wearing had become politicized and many communication messengers differed in their opinions on the worth of mask wearing, and thus neutralizing observability as a persuasive attribute.

\section{Implications/Reflection}

What transpired in the Spring of 2020 was a real-time exercise in processing an historical public health event. Students were highly engaged, had a personal connection, and were able to apply the concepts of 
DoI theory across several important public health recommendations. There was no course competency or learning objective tied to our discussions beyond the existing: "Address the concepts of population health, and the basic processes, approaches, and interventions that identify and address the major healthrelated needs and concerns of populations." With planning, however, the public health response to COVID-19 is an excellent real-time case example for an assignment developing or evaluating health communications or community interventions. DoI theory can be used by public health faculty to explain actions by the public and to help them better grasp the ways different audiences may "adopt" an innovation based on the theory attributes. While this class discussion was organic, additional ideas for assignments related to this topic include:

1. Have students choose an adopter category (e.g., late majority) and a characteristic (e.g., compatibility) and list 3 or 4 short text messages designed to get this category group to wear cloth masks during COVID-19 or a similar epidemic. To take this further, students could format the messages for certain social media.

2. Ask students to find 3 health communications aimed to reduce community spread of COVID19 and delivered by a government agency, e.g., the CDC, White House, local health department. In small groups, students should evaluate the messaging and score each piece on how well it addresses the 5 characteristics of DoI. Consider creating a worksheet for the students that gives the characteristic name with a brief description and a score of 1 to 5 . Each communication will have a sum of 5 scores, and the highest score would be the one that aligns to DoI the best.

3. Building on the above activity, students can revise one of the communications so that it does meet the best practices of DoI.

4. Have students create a multimodal program to increase adherence to all COVID-19 guidance at the time of the exercise (i.e., guidance is dynamic), this could include a TV ad, social media, blitz, community meeting.

5. Spotlight an activity that the government has noted as high risk and have students create a health communication targeting people who would engage in that activity, e.g., indoor sports, using some or all of the DoI characteristics.

The suggested assignments could take place in a variety of courses, including program planning and evaluation, health communication, and behavior change theory.

\section{Conclusion}

In teaching most health-related professions, we have the opportunity to use current events in real-time to actively engage students and promote learning. While not all highly salient events provide as rich a landscape as COVID-19, the current environment is ripe for helping students understand that their work does not exist in a vacuum and that socio-political events can have significant effects on public reactions and beliefs in an ongoing event. Importantly, using these types of events in public health and health professions pedagogy can provide opportunities for lasting lessons that students can take into the workforce, including how to use theory, like DoI, to better plan for and understand the public's reaction and behavior.

\section{Disclosures and Conflicts of Interest}

The authors have no conflicts to disclose.

\section{Acknowledgments}

We acknowledge the students past, present and future of SBS 3496/3596. 


\section{References}

1. Chau JPC, Lo SHS, Choi KC, et al. Factors determining the uptake of influenza vaccination among children with chronic conditions. The Pediatric Infectious Disease Journal. 2017;36(7):e197e202.

2. Dilorio C, Dudley WN, Soet J, Watkins J, Maibach E. A social cognitive-based model for condom use among college students. Nursing Research. 2000;49(4):208-214.

3. Parkes SD, Marsden G, Shaheen SA, Cohen AP. Understanding the diffusion of public bikesharing systems: evidence from Europe and North America. Journal of Transport Geography. 2013;31:94-103.

4. Lien ASY, Jiang YD. Integration of diffusion of innovation theory into diabetes care. Journal of Diabetes Investigation. 2017;8(3):259.

5. Glanz K, Rimer BK, Viswanath K. Health Behavior and Health Education: Theory, Research, and Practice. John Wiley \& Sons; 2008.

6. $\quad$ Rogers EM. Diffusion of Innovations, 4th Edition. Free Press; 2010.

7. Kapoor KK, Dwivedi YK, Williams MD. Rogers' innovation adoption attributes: A systematic review and synthesis of existing research. Information Systems Management. 2014;31(1):74-91.

8. Valente TW, Fosados R. Diffusion of innovations and network segmentation: The part played by people in promoting health. Sexually Transmitted Diseases. 2006;33(7):S23-S31.

9. Keni R, Alexander A, Nayak PG, Mudgal J, Nandakumar K. COVID-19: Emergence, spread, possible treatments, and global burden. Frontiers in Public Health. 2020;8

10. City of Philadelphia. Non-essential businesses to close until further notice. 2020, March 17. Accessed October 14, 2020. https://www.phila.gov/2020-03-17-non-essential-businesses-toclose-for-at-least-two-weeks/

11. Commonwealth of Pennsylvania. All non-life sustaining businesses in Pennsylvania to close physical locations as of 8PM today to slow spread of CPVOD-19. 2020, March 19. Accessed October 14, 2020. https://www.governor.pa.gov/newsroom/all-non-life-sustainingbusinesses-in-pennsylvania-to-close-physical-locations-as-of-8-pm-today-to-slow-spread-ofcovid-19/

12. Schuchat A. Public health response to the initiation and spread of pandemic COVID-19 in the United States, February 24-April 21, 2020. MMWR Morbidity and Mortality Weekly Report. 2020;69

13. McNerthney C. Coronavirus in Washington state: A timeline of the outbreak through March 2020. KIRO 7 News. Accessed October 20, 2020. https://www.kiro7.com/news/local/coronavirus-washington-state-timelineoutbreak/IM65JK66N5BYTIAPZ3FUZSKMUE/

14. Smalley A. Higher education responses to Coronavirus (COVID19). National Conference of State Legislatures; 2020, July 27. Accessed October 20, 2020. . https://www.ncsl.org/research/education/higher-education-responses-to-coronavirus-covid19.aspx

15. Bass SB, Scarpulla MC, Patterson F, Watts SO, Twersky S. Integrating liberal arts learning outcomes in the development and implementation of a multisection undergraduate public health capstone course. Pedagogy in Health Promotion. 2017;3(1):16-22.

16. Igielnik R. Most Americans say they regularly wore a mask in stores in the past month; fewer see others doing it.: Pew Research Center; 2020, June 23. Accessed October 14, 2020. https://www.pewresearch.org/fact-tank/2020/06/23/most-americans-say-they-regularlywore-a-mask-in-stores-in-the-past-month-fewer-see-others-doing-it/

17. Goodnough A, Sheikh K. C.D.C Weighs advising everyone to wear a mask. New York Times. Accessed October 20, 2020. https://www.nytimes.com/2020/03/31/health/cdc-maskscoronavirus.html 
18. Centers for Disease Control and Prevention.. COVID-19: Considerations for wearing cloth face coverings. 2019. Accessed October 14, 2020. https://www.cdc.gov/coronavirus/2019ncov/prevent-getting-sick/cloth-face-cover-guidance.html

19. Lacina L. Should you wear a face mask? WHO officials weigh in at today's COVID-19 briefing. World Economic Forum; 2020, March 30.

20. Mandavilli A. 239 experts with one big claim: The coronoavirus is airborne. https://www.nytimes.com/2020/07/04/health/239-experts-with-one-big-claim-thecoronavirus-is-airborne.html

21. Eikenberry SE, Mancuso M, Iboi E, et al. To mask or not to mask: Modeling the potential for face mask use by the general public to curtail the COVID-19 pandemic. Infectious Disease Modelling. 2020;

22. Markel H, Stern AM, Navarro JA, Michalsen JR, Monto AS, DiGiovanni Jr C. Nonpharmaceutical influenza mitigation strategies, US communities, 1918-1920 pandemic. Emerging Infectious Diseases. 2006;12(12):1961.

23. Centers for Disease Control and Prevention a. How to wear cloth face coverings.: Centers for Disease Control and Prevention; 2020, March 22.

24. Kreiger J. 8 common coronavirus mask styles that don't actually protect against coronavirus.: NBC Think; 2020, June 30.

25. Lyu W, Wehby GL. Community Use Of Face Masks And COVID-19: Evidence From A Natural Experiment Of State Mandates In The US. Health Aff (Millwood). 08 2020;39(8):1419-1425. doi:10.1377/hlthaff.2020.00818

\section{Statement of Contributions}

$\mathrm{DAD}$ is responsible for the paper concept, the case study, and initial draft; SBB was content expert and editor. 